\title{
Measured gas desorption and electron cloud effects with an intense ion beam in a solenoid lattice
}

\author{
J. E. Coleman \\ Department of Nuclear Engineering, University of California at Berkeley, 4155 Etcheverry Hall, MC 1730, \\ Berkeley, California 94720, USA, \\ and Lawrence Berkeley National Laboratory, 1 Cyclotron Road, Berkeley, California 94720, USA \\ P. A. Seidl and J. L. Vay \\ Lawrence Berkeley National Laboratory, 1 Cyclotron Road, Berkeley, California 94720, USA
}

A. W. Molvik and W. M. Sharp

Lawrence Livermore National Laboratory, Livermore, California 94550, USA

(Received 14 October 2007; published 7 May 2008)

\begin{abstract}
Electron cloud and gas measurements were conducted in a solenoid lattice with a $10 \mu \mathrm{s}$, singly charged $\mathrm{K}^{+}$ion bunch at an ion energy of $0.3 \mathrm{MeV}$ and currents of 26 and $45 \mathrm{~mA}$. The principal objective of these experiments is to control electrons and understand their impact on the beam dynamics. Electron clearing measurements indicate an electron density close to $1 \%$ of the beam density in the solenoid lattice is enough to partially neutralize the beam and cause the emittance to grow $\geq 40 \%$. A new method of measuring the dynamics of beam-induced gas desorption, ionization, and electron emission for normal incidence is also presented. Stainless steel and copper targets exposed to a beam intensity of $1.6 \times$ $10^{12}$ ions/pulse show ionized gas and electron densities approach the beam density in a single pulse. These measurements also show the gas cloud expands as a function of time and the dynamics are dependent upon the incident material and the bias voltage.
\end{abstract}

DOI: 10.1103/PhysRevSTAB.11.050103

PACS numbers: 52.59.Sa, 29.27.Bd, 29.30.Aj, 34.35.+a

\section{INTRODUCTION}

Space-charge dominated ion beams used in an accelerator to drive fusion targets face a number of unique challenges. One of particular interest to the general accelerator community is beam degradation, such as emittance growth, due to electron cloud and gas effects [1-10]. Mismatched portions of a beam, such as beam halo, photons, and even matched portions of a beam incident upon a material in the path of the particle desorbs gas and electrons [11-20]. The desorbed gas expands into the beam path close to the sound speed and subsequently becomes ionized [21]. In some cases the electron and ionized neutral densities are assumed to approach the beam density and significant changes in the charge collected on diagnostics, emittance growth, and fluctuations in the beam envelope are seen $[22,23]$.

Measurements of gas desorption and electron emission for ion beams at normal incidence have been made in the past with 50-225 $\mathrm{keV}$ protons [24], 28-MeV protons, 126$\mathrm{MeV} \mathrm{O}^{8+}$ ions, and $182-\mathrm{MeV} \mathrm{Au}^{31+}$ ions [25], 869-MeV $\mathrm{Pb}^{27+}$ and $\mathrm{Pb}^{53+}$ ions [26,27], and 3.6-23.8 $\mathrm{GeV} \mathrm{U}^{73+}$ ions $[28,29]$. All of these measurements vary widely as expected due to parametric differences. The beam energy of each of the cases is right around or well above the Bragg peak, however the intensity (current) of these beams is fairly low. Recent measurements with a high intensity $\left(4.5 \times 10^{12}\right.$ ions/pulse) $1 \mathrm{MeV} \mathrm{K}^{+}$ion beam normally incident on a stainless steel target, well below the Bragg peak, show a gas desorption rate of $\sim 3000 \mathrm{H}_{2}$ molecules $/ \mathrm{K}^{+}$ion [21].

The neutralized drift compression experiment (NDCX) at LBNL is exploring the physical limits of compression and focusing of ion beams for heating material to warm dense matter (WDM) and inertial fusion ignition conditions [30-32]. Low emittance is necessary in order to attain beam intensities necessary for heating targets. In preparation for NDCX, the solenoid transport experiment (STX) is studying electron cloud effects in solenoids and understanding their impact on the beam dynamics of a singly charged, $300-\mathrm{kV}, 26-45 \mathrm{~mA}$ potassium ion beam (intensity $\sim 2 \times 10^{12}$ ions/pulse). Beam transport of space-charge dominated ion beams with solenoids, unlike magnetic quadrupoles, have predominant axial fields in the center of the magnets and large radial fields at the fringe. These large fringe magnetic fields help pull electrons into the beam and present difficulties in suppressing electrons when intercepting the beam with diagnostics [23]. However, this particular field arrangement also presents an opportunity to suppress and clear electrons using cylindrical electrodes, which intercept magnetic field lines. A new method of directly measuring the dynamics of beaminduced gas desorption, ionization, and electron emission for normal incidence is also presented.

\section{FOUR-SOLENOID EXPERIMENT}

Two more solenoids were added to the already existing two-solenoid lattice on the NDCX beam line (Fig. 1). The 


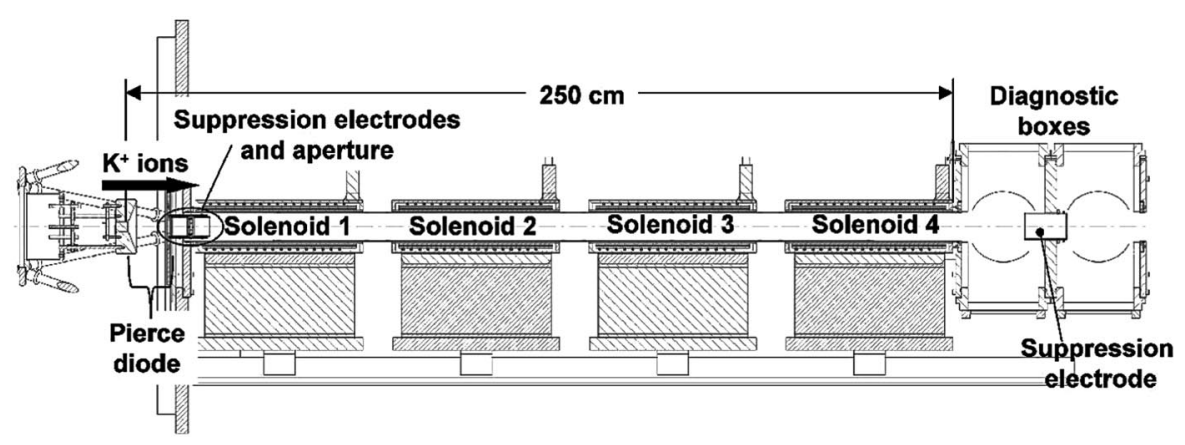

FIG. 1. Elevation view of the four-solenoid experiment.

two additional solenoids were also 50-cm long, had an identical construction to those used in the two-solenoid experiments, and the spacing in between all of the magnets was about $9 \mathrm{~cm}[23,33]$.

The beam used for these experiments was accelerated through a 12-cm Pierce diode (Fig. 1) by a $300 \mathrm{kV}, 10-\mu \mathrm{s}$ long voltage pulse (Fig. 2). Two cylindrical electron suppression electrodes, with a removable current-reducing aperture between them, followed directly downstream. The fully extracted beam current measured $54 \mathrm{~cm}$ downstream of the exit of four solenoids $(z=304 \mathrm{~cm})$ with a $6.35 \mathrm{~cm}$ diameter Faraday cup was about $45 \mathrm{~mA}$ (Fig. 2). Installing the $2-\mathrm{cm}$ diameter aperture reduced the current at $300 \mathrm{kV}$ from 45 to $26 \mathrm{~mA}$. The current signals are displaced in time relative to the Marx voltage pulse due to the time of flight of the beam to the collector. Measurements showed a peak in the signal at the beginning of the pulse due to overtaking in the beam head. The observation that the large fringe magnetic field aided electron confinement and contributed to the sheath formation and electron cloud effects in degrading the beam quality in the two-solenoid experiment was accounted for in this four-solenoid lattice.

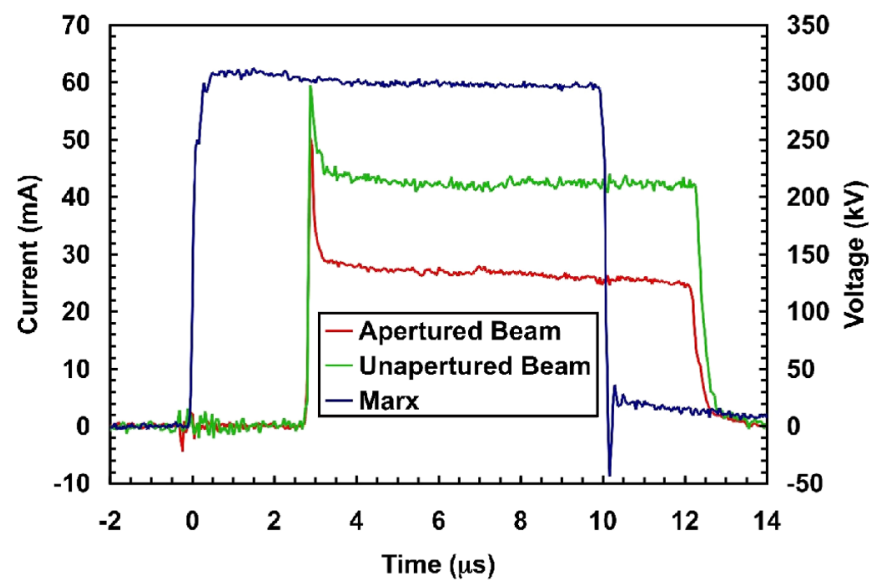

FIG. 2. (Color) Marx voltage waveform used to extract the beam through the diode (blue) and the measured beam current $54 \mathrm{~cm}$ downstream of the exit of four solenoids $(z=304 \mathrm{~cm})$ with the aperture installed (red) and without the aperture installed (green).
So the intercepting diagnostics were placed nearly $40 \mathrm{~cm}$ downstream of the exit of the four-solenoid lattice where the axial field was $\sim 100 \mathrm{G}$ or negligible. Transverse phase space measurements were made using two separate diagnostic techniques. One method used an upstream slit and a downstream slit and a Faraday collector (slit cup). The second method used a $100-\mu \mathrm{m}$ thick alumina scintillator and an image-intensified gated-CCD camera that imaged beam-induced light emission after masking the beam with a single upstream slit [34]. The transverse beam distribution $[J(x, y)]$ was also measured using beam-induced light emission from the scintillator. A more detailed explanation of the diagnostics is in Ref. [23].

\section{A. Apertured beam measurements}

Initial tests with the four-solenoid lattice were done with a current-reducing aperture that reduced the 45-mA beam to $26 \mathrm{~mA}$. The focusing lattice in Fig. 3(a) was chosen to give the desired envelope for the 26-mA beam in Fig. 3(b). Despite diagnosing the beam in a low $(\sim 100 \mathrm{G})$ magnetic field, the measured emittance for the apertured beam was $80 \%$ larger than what was measured directly downstream of the gun without any solenoid focusing (Fig. 4). The beam envelope also had slight time dependence but the envelope remained converging and the variation in radius was less than $2 \mathrm{~mm}$ (Fig. 5). The observed time dependence hints there might be partial neutralization of the beam due to electrons.

The waveforms in Fig. 5 are calculated from signal levels $\sim$ millivolt which have a low $S / N$. The spikes just after $3 \mu \mathrm{s}$ and just before $13 \mu \mathrm{s}$ are due to the head and tail of the beam pulse. The spike after $10 \mu \mathrm{s}$ corresponds to amplified electrical noise from the crowbar spark gap firing to terminate the Marx voltage pulse at $10 \mu$ s (Fig. 2).

It is known from past experiments without any solenoid focusing and with magnetic quadrupole focusing once the beam strikes the current-reducing aperture, unwanted gas can be desorbed and ionized adding unwanted electrons and ions into the diode and focusing lattice [35]. That is why there are two cylindrical electrodes, each on either side of the aperture biased at $-3 \mathrm{kV}$ to effectively suppress 

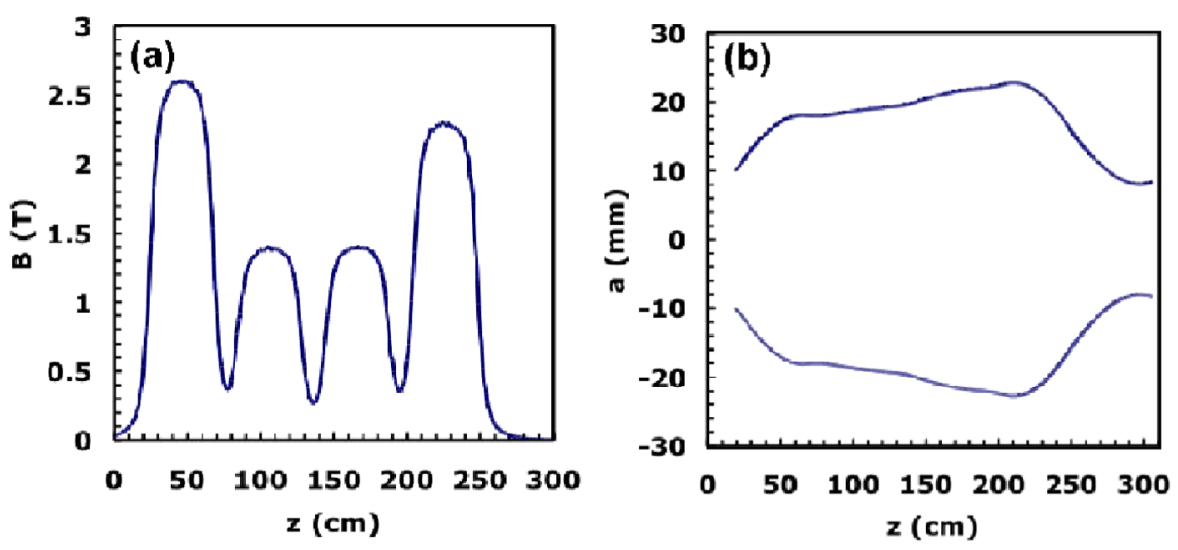

FIG. 3. (Color) (a) Axial magnetic field profile based on measurements; (b) calculated envelope for the apertured 26-mA beam.
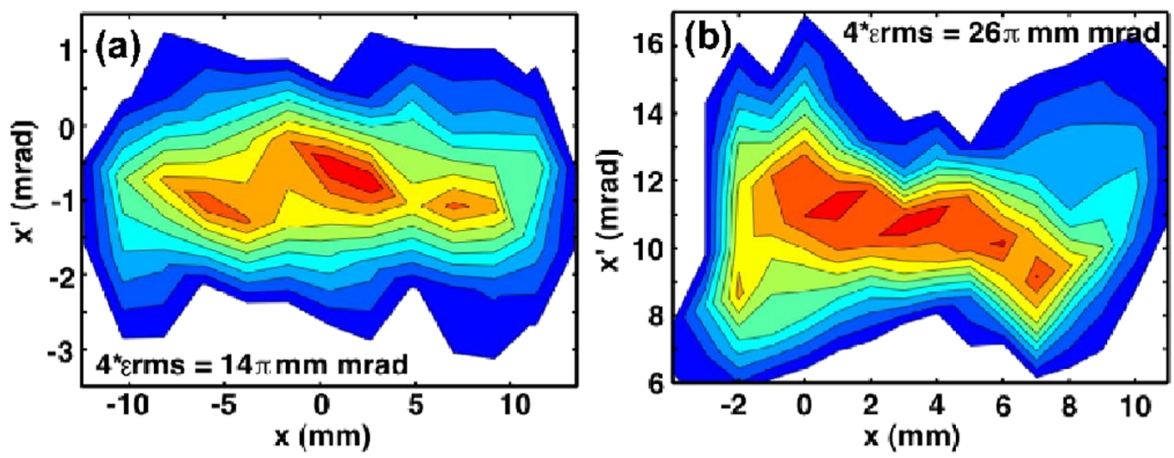

FIG. 4. (Color) Sheared phase space distribution integrated over a $500 \mathrm{~ns}$ gate in the middle of the $10 \mu \mathrm{s}$ beam pulse: (a) $15 \mathrm{~cm}$ downstream of the exit of the extractor $(z=27 \mathrm{~cm}$; without solenoid focusing); (b) $40 \mathrm{~cm}$ downstream of the exit of four solenoids ( $z=290 \mathrm{~cm}$; note scale differences).

electrons. As stated above, the large fringe magnetic fields from the solenoids present difficulties in suppressing electrons particularly when the beam is normally incident upon an object, like the aperture. These observations indicated the electrodes surrounding the aperture might not be suppressing electrons effectively. In the next two sections,

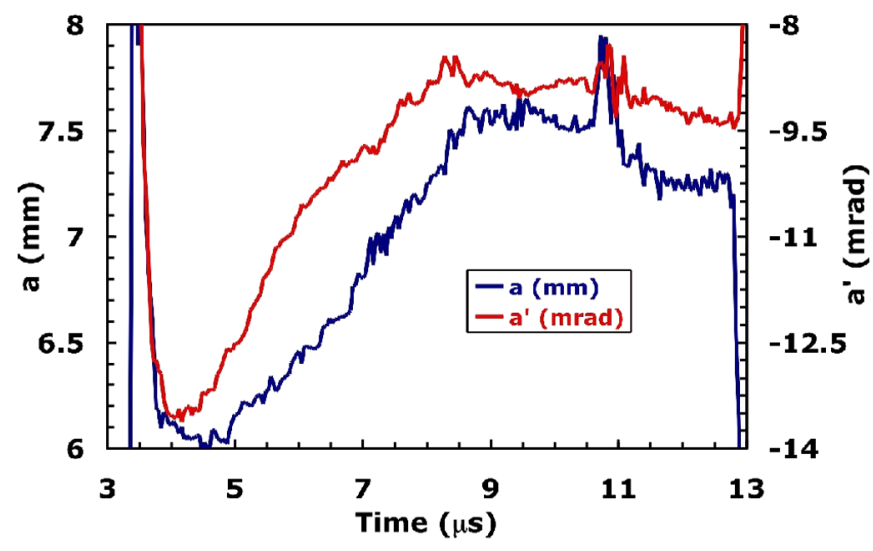

FIG. 5. (Color) Beam envelope $40 \mathrm{~cm}$ downstream of the exit of four solenoids as a function of time $(z=290 \mathrm{~cm})$. measurements with electron cloud diagnostics will show how these effects can be mitigated.

\section{B. Apertured beam measurements with electron cloud diagnostics}

Extensive studies of electron cloud and gas effects in the four-solenoid lattice were done with the apertured 26-mA beam using new cylindrical electrodes inside the beam pipe (electron cloud diagnostics; Fig. 6). These electron cloud diagnostics consisted of 4 short ( $8.45-\mathrm{cm}$ long) cylindrical electrodes in the center of each solenoid magnet (solenoid electrodes 1, 3, 5, and 7) and the 3 longer (25.4-cm long) cylindrical electrodes in the gaps between magnets (gap electrodes 2, 4, and 6). These electrodes are short compared to the beam bunch length $\left(\sim 1.2 \times 10^{3} \mathrm{~cm}\right)$ and have a radius $(3.6 \mathrm{~cm})$ slightly smaller than the beam pipe radius of $4.3 \mathrm{~cm}$. The gap electrodes were strategically placed to intercept the maximum amount of expanding magnetic flux between magnets (Fig. 6). The 13-cm long cylindrical electrode that was just upstream of the intercepting diagnostics (Fig. 1) was moved $29 \mathrm{~cm}$ upstream into the exit of solenoid 4 (electrode 8; Fig. 6) to intercept the expanding magnetic flux at the exit of solenoid 4 , 


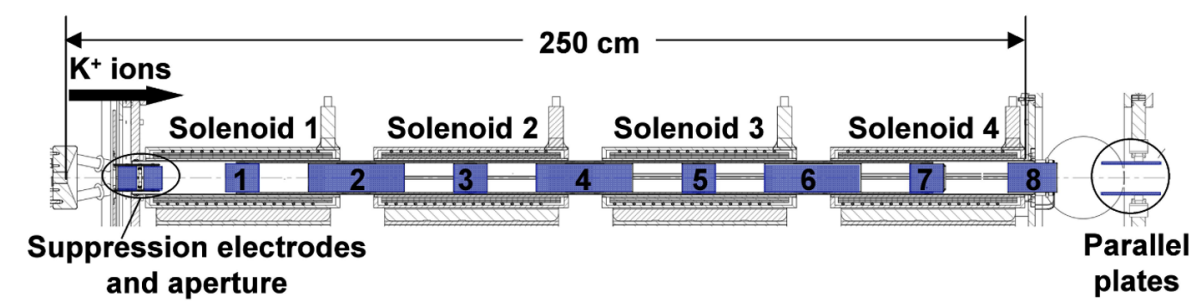

FIG. 6. (Color) Layout of the aperture and suppression electrodes, electron cloud diagnostics: solenoid electrodes (1, 3, 5, and 7), gap electrodes $(2,4,6$, and 8$)$; and parallel plate diagnostic relative to the four-solenoid lattice. All the diagnostics have cylindrical symmetry except for the parallel plate diagnostic.

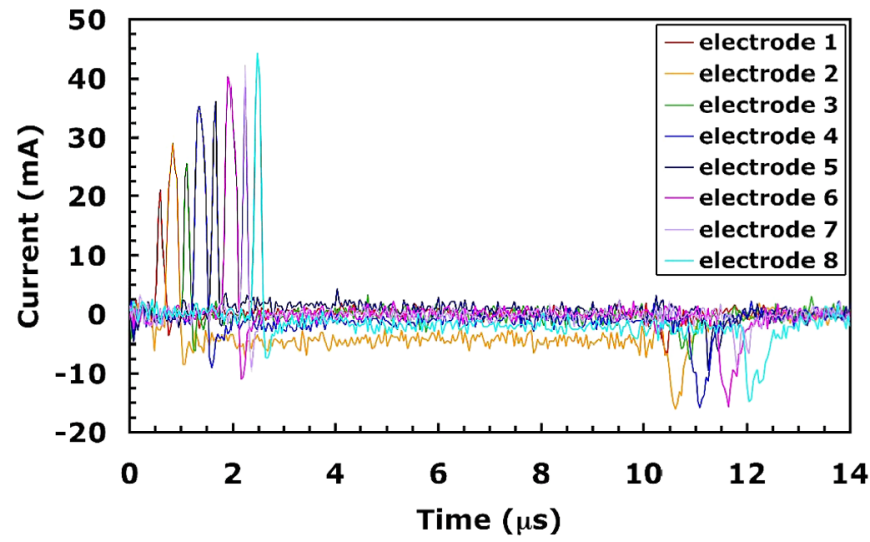

FIG. 7. (Color) Electron cloud diagnostic signals as a function of time.
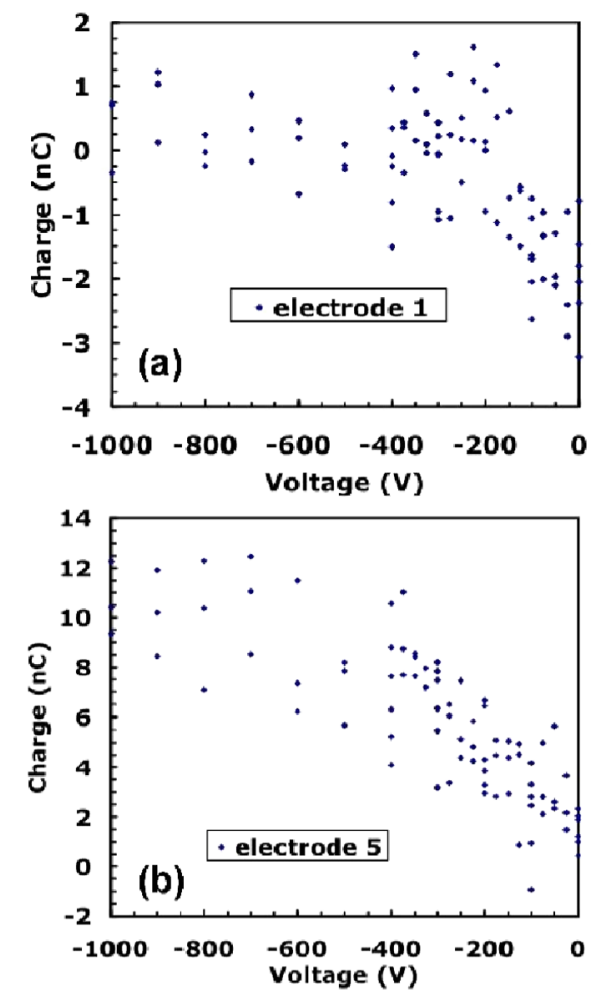

making electrode 8 have a similar function to a gap electrode. A pair of parallel plates was used in place of this cylindrical electrode just upstream of the intercepting diagnostics to suppress electrons and measure the dynamics of beam-induced gas desorption, ionization, and electron emission.

These cylindrical electrodes measured a positive capacitive image current of the beam as it entered the diagnostic and negative capacitive image current of the beam as it exited (Fig. 7). These capacitive signals are proportional to the derivative of the beam current. Similar to the current measured by the Faraday cup in Fig. 2, the signals are displaced in time due to the time of flight of the beam to each electrode. The width of the spikes alternated between narrow and wider, corresponding to the short solenoid electrodes (1, 3, 5, and 7) and the longer gap electrodes $(2,4,6$, and 8$)$. Measurements showed a growth in the peak
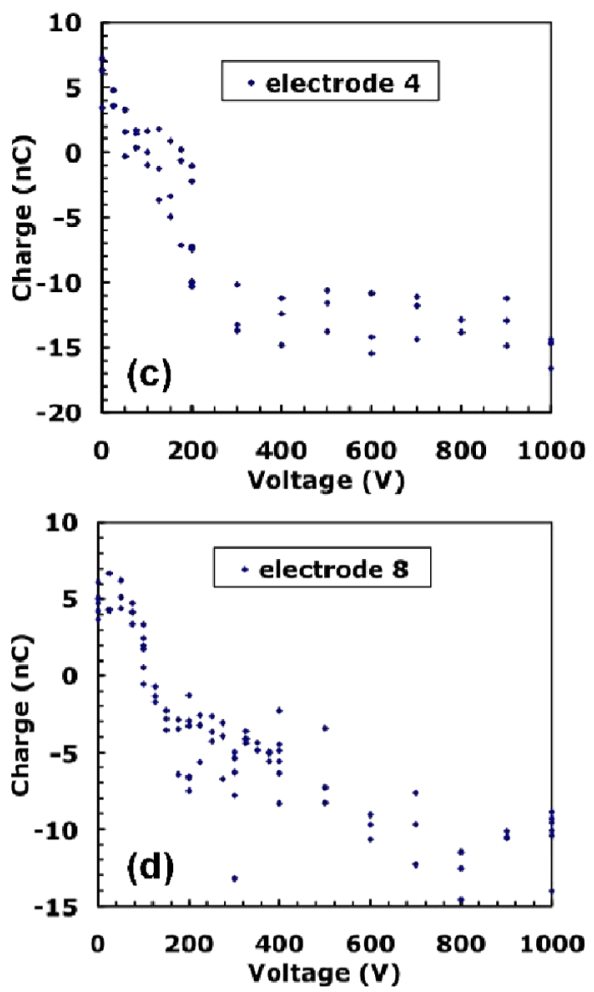

FIG. 8. (Color) Charge collected as a function of bias voltage for: (a) electrode 1; (b) electrode 5; (c) electrode 4; (d) electrode 8. 


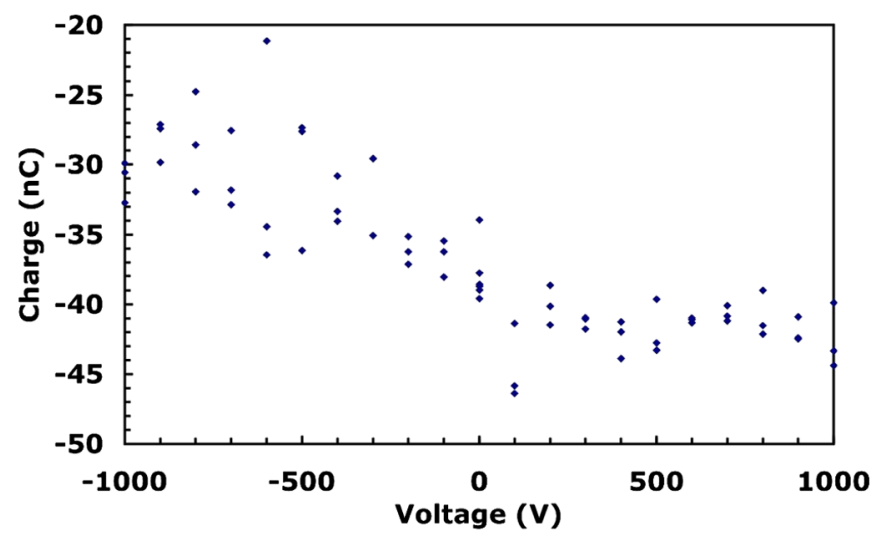

FIG. 9. (Color) Charge collected as a function of bias voltage for electrode 2 . of the positive capacitive signal as the beam propagated axially due to overtaking in the beam head. The electrodes collected charge throughout the pulse depending on the bias configuration and location of the diagnostic along the focusing lattice.

These electrodes were independently biased between $\pm 1 \mathrm{kV}$. The solenoid electrodes (1, 3, 5, and 7) were biased negatively to repel electrons, while the gap electrodes $(2,4,6$, and 8) were biased positively to clear electrons from intercepted field lines and suppress emission. Reversing the biases trapped electrons that were emitted from the gap electrodes between magnets. Results of operating the diagnostics to clear electrons from the lattice showed charge collection began to saturate for voltage biases $|V| \geq 600 \mathrm{~V}$ (Fig. 8).
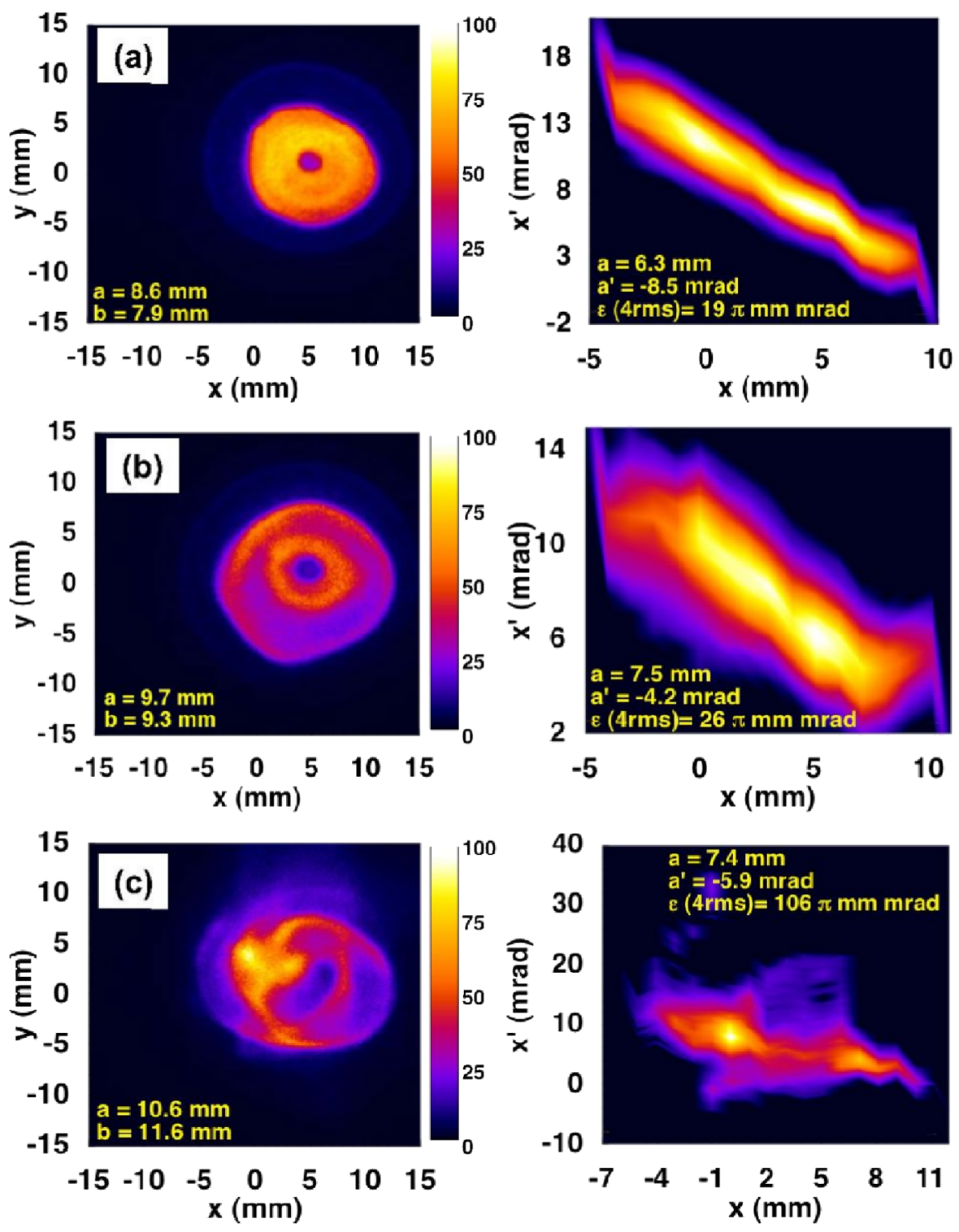

FIG. 10. (Color) Left column: measured transverse beam distribution $56 \mathrm{~cm}$ downstream of the exit of four solenoids $(z=306 \mathrm{~cm})$; right column: measured transverse phase space $40 \mathrm{~cm}$ downstream of the exit of four solenoids $(z=290 \mathrm{~cm}$; note scale differences) for: (a) clearing case; (b) grounded case; (c) trapping case. 
The data points for the charge collected on each of the 8 electrodes were provided by three or more consecutive shots at each bias voltage. This demonstrates the shot to shot variation at each voltage and a general trend for each electrode. Electrodes 1 and 5 were biased negatively to repel electrons, the positive charge collected on electrode 5 is most likely stray ions from gas ionized in the lattice by the beam ions or electrons with sufficient energy.

Some of the evidence that the electrodes surrounding the aperture were not sufficiently suppressing electrons was seen from the charge collected on the most upstream gap electrode 2 (Fig. 9). Electrons were collected on this electrode regardless of the bias voltage and the threshold was reached just above $+100 \mathrm{~V}$. This electrode was magnetically connected to the aperture, because most of the field lines from the first solenoid intersected this electrode and the electrode directly downstream of the aperture. Any electrons made by beam and gas interactions at the aperture were tied to these field lines and collected on electrode 2 .

The amount of current (charge/pulse length) collected on electrode 2 (Fig. 7) was used to quantify the line charge density of electrons $\left(\lambda_{e}=\mathrm{I}_{e} / \mathrm{v}_{e}\right)$ relative to the beam line charge density $\left(\lambda_{b}\right)$ and provide an estimate of the electron density in the solenoid lattice contributed by the beam and gas interactions at the aperture. Assuming the electrons collected on electrode 2 have purely kinetic energy ( $4 \mathrm{keV}$ ) provided by the potential difference from the suppression electrode at the aperture to electrode 2 , then $\lambda_{e}=$ $107 \mathrm{pC} / \mathrm{m}$. Including the electron current from electrodes
4 and 8 increases $\lambda_{e}$ to $200 \mathrm{pC} / \mathrm{m}$. This is $\sim 1 \%$ of $\lambda_{b}$ $(21 \mathrm{nC} / \mathrm{m})$ and suggests an electron density, $\mathrm{n}_{e} \sim$ $106 \mathrm{~cm}^{-3}, 1 \%$ of the beam density $\left(\mathrm{n}_{K+} \sim 10^{8} \mathrm{~cm}^{-3}\right)$ might be present in the solenoid lattice.

The impact of clearing electrons on the beam quality was evident from optical measurements of the transverse beam distribution $[J(x, y)]$ and phase space (Fig. 10). The transverse beam distribution of the clearing case had a smaller circular distribution compared to the larger and more irregular shapes of the other two cases. Grounding the electrodes matched the unnormalized emittance measured in Fig. 4(b) without any electron cloud clearing. However, it was almost $40 \%$ greater than the clearing case, where electrons were collected in the gaps between solenoids, and trapping electrons inside the solenoids increased the unnormalized emittance of the clearing case by more than a factor of 5. Despite the reduced emittance from electron clearing, the beam quality was not as desired with a large ( $>5 \mathrm{~mm}$ ) centroid offset, $>25 \%$ beam halo, and a hollow nonaxisymmetric distribution. The likely causes of the degradation in the beam quality are discussed elsewhere $[23,36-38]$.

Further evidence of efficient clearing of electrons was shown in separate time-dependent phase space measurements of the beam (Fig. 11). The sheared transverse phase space of the clearing case had a fairly uniform distribution compared to the larger and more distorted shape of the case where the electrodes were grounded. Again the case where the electrodes were grounded had a larger emittance compared to collecting electrons in the gaps between solenoids
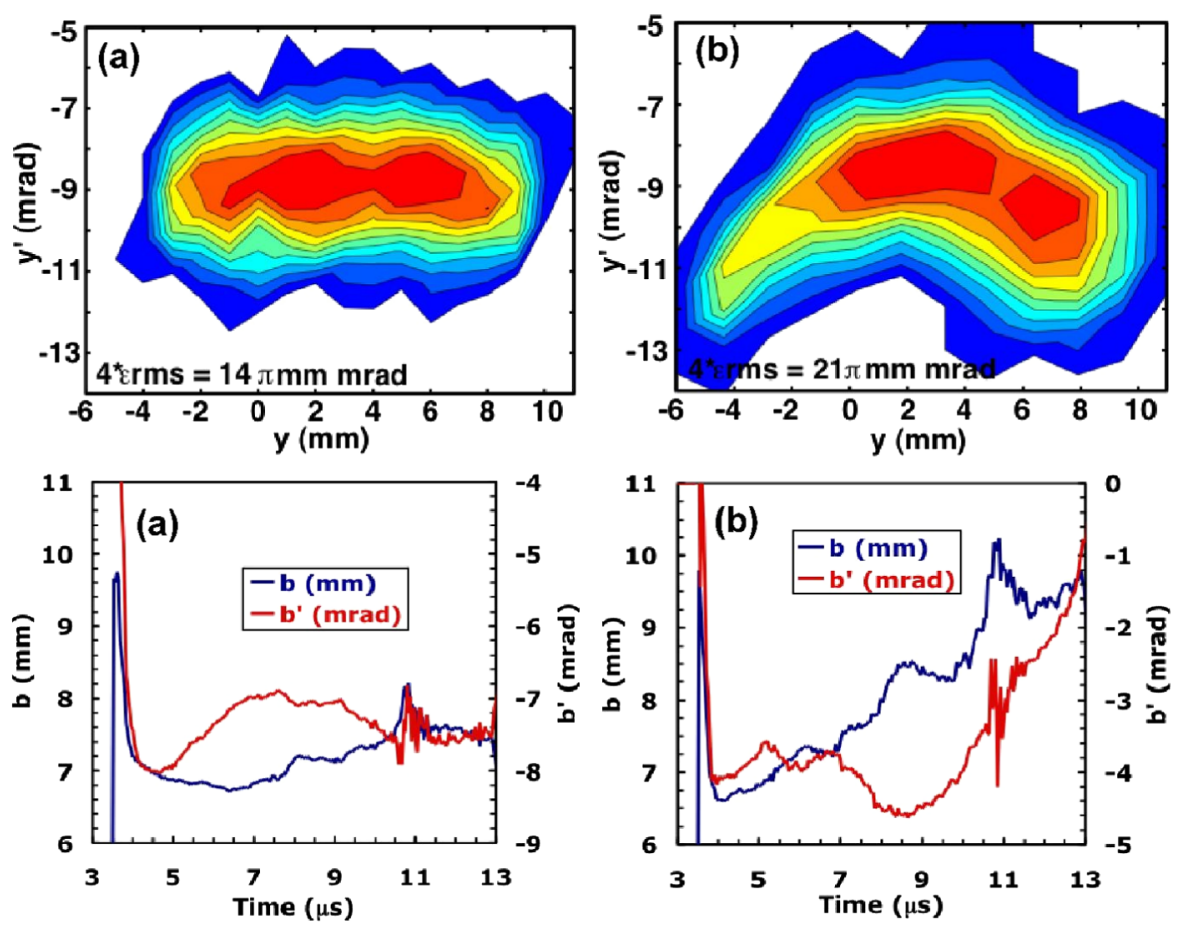

FIG. 11. (Color) Top row: measured sheared phase space distribution; bottom row: measured envelope as a function of time for: (a) clearing case; (b) grounded case; all $40 \mathrm{~cm}$ downstream of the exit of four solenoids $(z=290 \mathrm{~cm})$. 

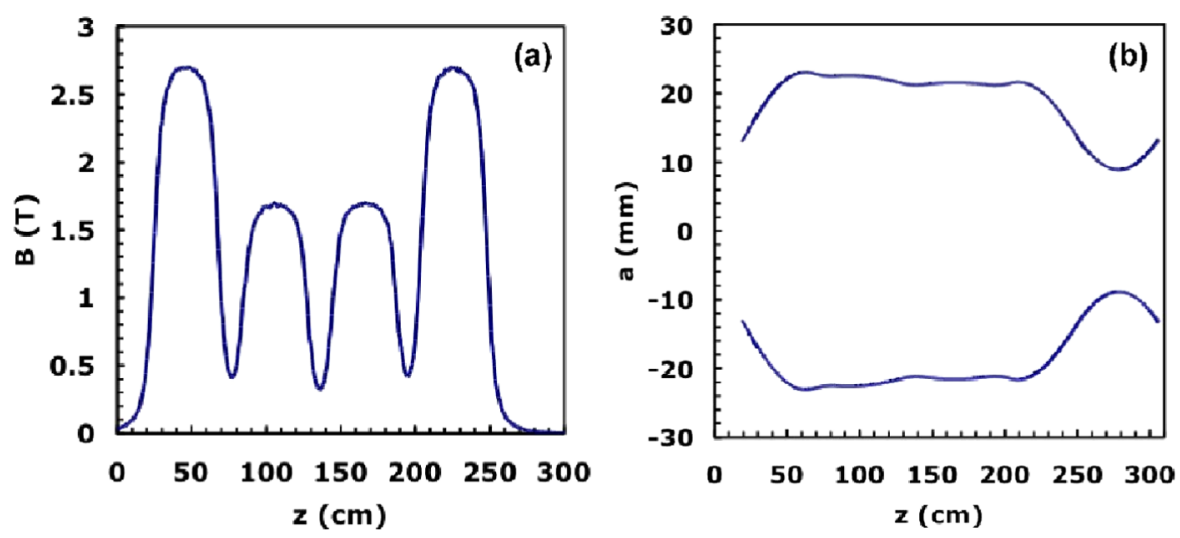

FIG. 12. (Color) (a) Axial magnetic field profile based on measurements; (b) calculated envelope of 45-mA beam.

(clearing), which matched the emittance of the beam extracted from the diode in Fig. 4(a) (14 $\pi$ mm mrad). The emittance from optical measurements is $>20 \%$ larger than the time-dependent phase space measurements but the trend of electron clearing is the same. Clearing electrons also removed the time dependence in the beam envelope and parameters agreed well with values calculated by solving the envelope equation in Fig. 3(b). The variation in the beam envelope of the clearing case on the left was within the resolution of the measurement, which is less than a millimeter and a milliradian. Similar to Fig. 5, the spikes in Fig. 11 just after $3 \mu$ s and just before $13 \mu$ s are due to the head and tail of the beam pulse. The spike after $10 \mu$ s corresponds to amplified electrical noise from the crowbar spark gap firing to terminate the Marx voltage pulse at $10 \mu$ s (Fig. 2).

The time dependence observed in the beam envelope without clearing electron clouds was likely due to partial neutralization of the beam space charge. If the electron density was high enough at any location in the lattice that portion of the beam envelope would have focused more easily as was also seen in the two-solenoid experiment [23]. The results of these time-dependent measurements (Fig. 11) and the optical measurements (Fig. 10) demonstrate the impact of clearing electrons. Combining these results with the measured ratio of $\lambda_{e} / \lambda_{b} \sim 1 \%$ when clearing electrons confirms partial neutralization as low as $1 \%$ can cause the observed increase in emittance. This also makes the case stronger that the aperture is the leading source of electrons and gas and the electrodes surrounding it are ineffective alone as electron suppressors in a solenoid lattice.

\section{Unapertured beam measurements with electron cloud diagnostics}

The evidence that the aperture was a leading source of electrons and gas was complemented with measurements without the aperture. Removing the aperture increased the current from 26 to $45 \mathrm{~mA}$, so a slightly different focusing strength [Fig. 12(a)] had to be used in the lattice to com- pensate for the higher beam current and in order to yield an envelope that did not scrape [Fig. 12(b)]. To provide a beam that was not too large to measure at the focal plane, a radius of $\leq 25 \mathrm{~mm}$ in the solenoid lattice was chosen. The magnetic field strength of solenoids 1 and 4 were increased to $2.7 \mathrm{~T}$ and solenoids 2 and 3 were increased by the square root of the current ratio $(\sim 30 \%)$.

The measurements with the unapertured $45-\mathrm{mA}$ beam show there was an insignificant difference between the cases when the diagnostics were grounded versus when they were biased to clear electrons; and negligible charge was collected on the electron cloud diagnostics for the 45$\mathrm{mA}$ beam when compared with the clearing case for apertured 26-mA beam (Table I and Fig. 13). Electrodes 2, 4, 5, and 8 in Table I show the most significant differences in the charge collected on individual electrodes. Those electrodes with $2 \mathrm{nC}$ or less of collected charge were well within the electrical noise (error bars) of the measurements. This confirmed that clearing electrons might not be necessary if there is no other source of electrons and gas besides the aperture.

Examining the charge collected on the electrodes due to capacitive effects for the 45-mA beam demonstrated the

TABLE I. Comparison of the charge collected on the electron cloud diagnostics for the 45-mA beam and the apertured 26-mA beam for the clearing case.

\begin{tabular}{lccc}
\hline \hline Diagnostic & Voltage $(\mathrm{kV})$ & \multicolumn{2}{c}{ 26-mA beam } \\
Charge $(\mathrm{nC})$ & 45-mA beam \\
Charge $(\mathrm{nC})$
\end{tabular}



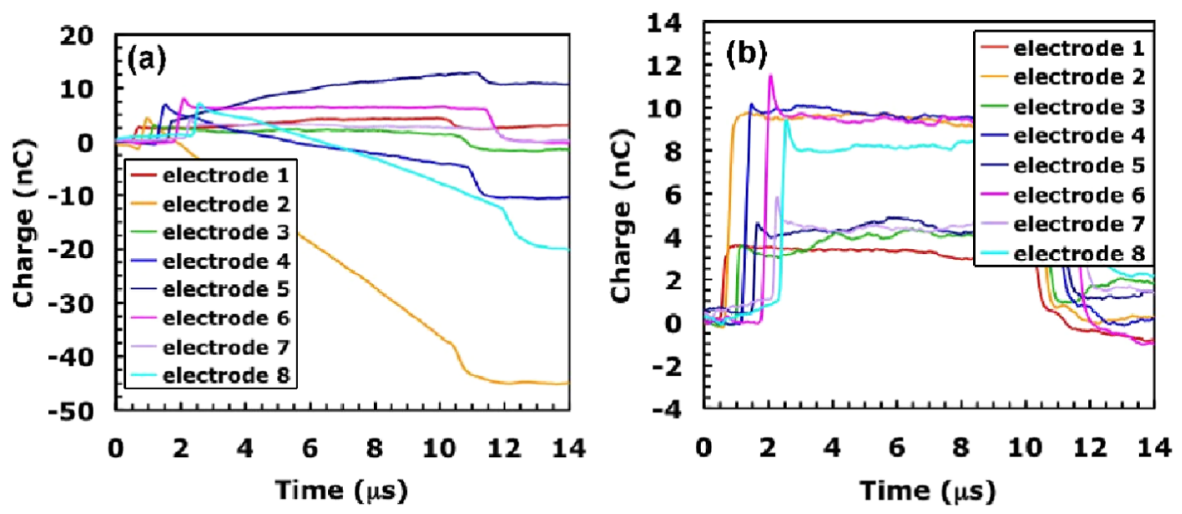

FIG. 13. (Color) Comparison of the charge collected on the electron cloud diagnostics for the: (a) apertured 26-mA beam and; (b) 45$\mathrm{mA}$ beam; both for the clearing case (note scale differences).
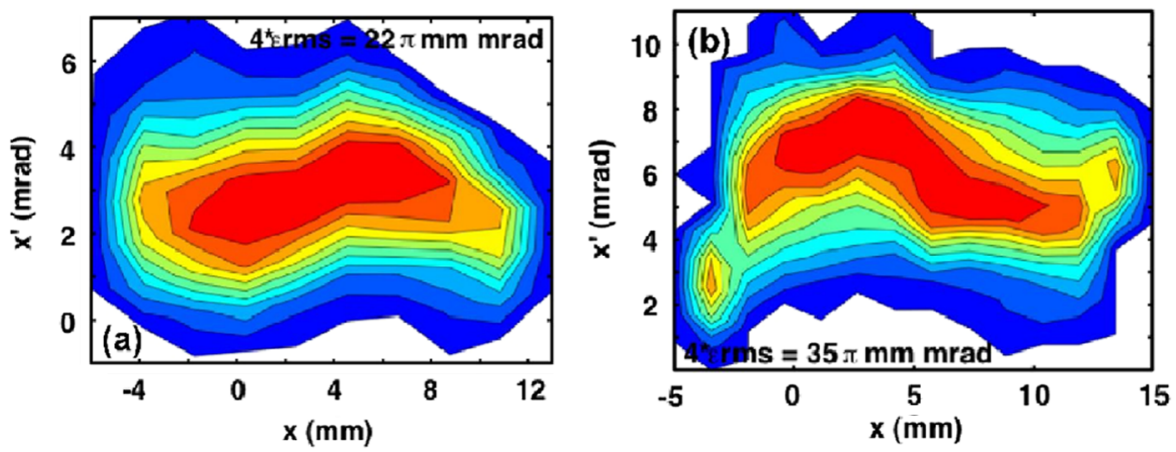

FIG. 14. (Color) Sheared phase space distribution of the unapertured $45-\mathrm{mA}$ beam integrated over a $500 \mathrm{~ns}$ gate in the middle of the $10 \mu$ s beam pulse: (a) $40 \mathrm{~cm}$ downstream of the exit of two solenoids $(z=171 \mathrm{~cm}$ ); (b) $40 \mathrm{~cm}$ downstream of the exit of four solenoids $(z=290 \mathrm{~cm}$; note scale differences).

difference in electrode length [Fig. 13(b)]. The shorter electrodes had $4 \mathrm{nC}$ of induced charge, while the longer electrodes showed about $10 \mathrm{nC}$. The accumulated charge (difference between end and beginning of beam pulse) for the unapertured case showed a $>10 \times$ reduction compared to the apertured beam, in spite of almost twice the beam current and a larger beam envelope (Table I).

The measurements without the aperture in this foursolenoid lattice showed a 50\% increase in emittance from that measured at the gun and after two solenoids (Fig. 14). As stated above, electron cloud effects appear to be small for this unapertured beam case and time dependence in the beam envelope is also small. The distortions in the phase space distribution (Fig. 14) help add to the emittance and are most likely due to the unstable centroid motion of the beam throughout the focusing lattice [23,37].

\section{QUANTIFYING ELECTRON EMISSION, GAS DESORPTION, AND IONIZATION}

A pair of polished stainless steel parallel plates $(15 \times$ 15) $\mathrm{cm}^{2}$ spaced about $7.5 \mathrm{~cm}$ apart (Fig. 15) and an intercepting diagnostic were used to make measurements of beam-induced gas desorption, ionization, and electron

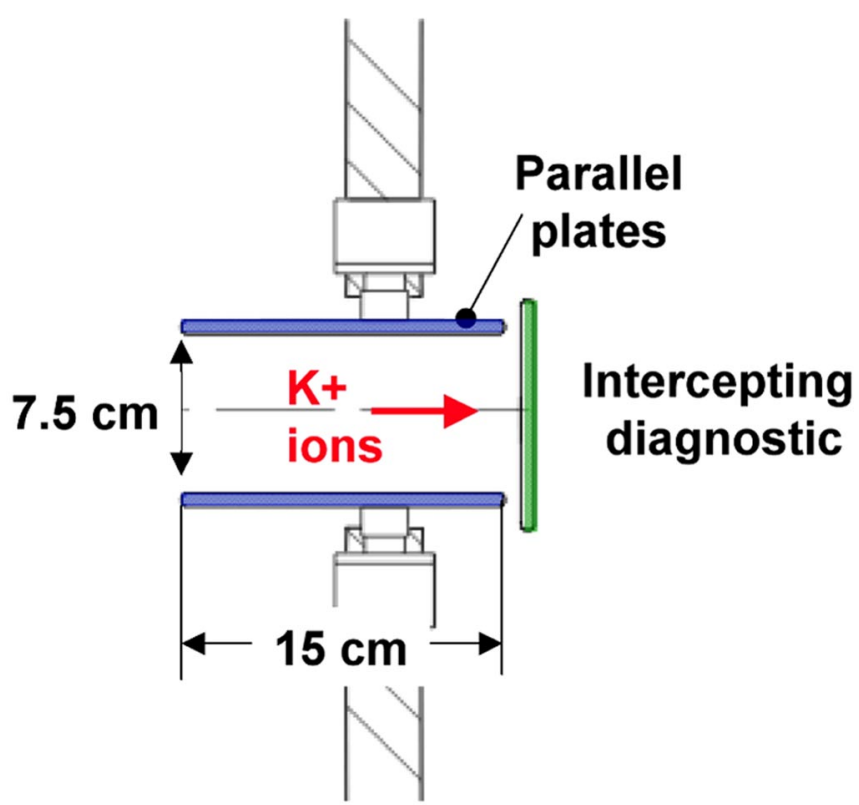

FIG. 15. (Color) Sketch of the experimental setup using the parallel plates and intercepting diagnostic to measure beaminduced gas desorption, ionization, and electron emission. 
emission with the apertured 26-mA beam. Two configurations were used with the parallel plates: first both plates were biased negatively to suppress electrons and second the plates were biased as a dipole with one plate biased positively to sweep electrons and the other grounded to collect some of the ionized gas. The parallel plates were placed $\sim 1 \mathrm{~cm}$ upstream of the intercepting diagnostic and biased from 0 to $10 \mathrm{kV}$ in $1 \mathrm{kV}$ intervals.

Two separate diagnostics, a stainless steel plate and a copper plate, were used in consecutive data sets to intercept the beam at $z=290 \mathrm{~cm}$. The purpose of using the two separate materials was to test whether the amount of gas desorbed and electrons emitted was strongly dependent on material composition. Each of the plates was at least 0.5$\mathrm{mm}$ thick and $4-\mathrm{cm}$ wide to fully accommodate the $1.5-\mathrm{cm}$ beam (Fig. 10). The plates were prepared in the same manner; they were chemically cleaned, first by degreasing at $50^{\circ} \mathrm{C}$ with ultrasonic agitation, followed by rinsing in cold demineralized water, rinsing with alcohol, and finally drying at room temperature. This method described is typical for any of our vacuum components.

As mentioned earlier, these experiments were conducted with a $10 \mu \mathrm{s}$, singly charged $\mathrm{K}^{+}$ion bunch at an ion energy of $0.3 \mathrm{MeV}$ and current of $26 \mathrm{~mA}$ providing $1.6 \times$ $10^{12}$ ions/pulse. The repetition rate of the ion pulse was flexible but was maintained at $0.05 \mathrm{~Hz}$. Target heating of the plates was negligible because the range of the ions at this energy (300 keV) is less than $1 \mu \mathrm{m}$. Our typical vacuum pressure, $4-5 \times 10^{-8}$ torr, was used in these experiments because we wanted to quantify beam-induced gas desorption, ionization, and electron emission for our normal operating conditions. No significant change in vacuum pressure was noted for these experiments.

The intercepting plates (targets) were capacitively monitored at $0 \mathrm{~V}$ and the signal provided with both parallel plates biased negatively was similar to, but not exactly the measured beam current due to nonbeam ion and electron species in the vicinity of the diagnostic (Fig. 16). Once the head of the beam had passed, after $3 \mu \mathrm{s}$, the beam current and envelope stabilized, and the number of emitted gas molecules and electrons should rise linearly over the relevant time frame $(10 \mu \mathrm{s})$ along with the collected current. This assumes that the size of the beam hitting the target is large enough that the gas expansion is negligible in the transverse direction.

\section{A. Ionized gas measurements}

With both parallel plates biased negatively, the gas desorbed from the intercepting plate and subsequently ionized was directly measured. Although this is a useful measurement, it would be more certain if the parallel plates were biased as a dipole with one plate biased negatively to collect all of the gas ions and the other grounded to collect some of the electrons. With both plates biased negatively, there is no field between the plates and it is possible that

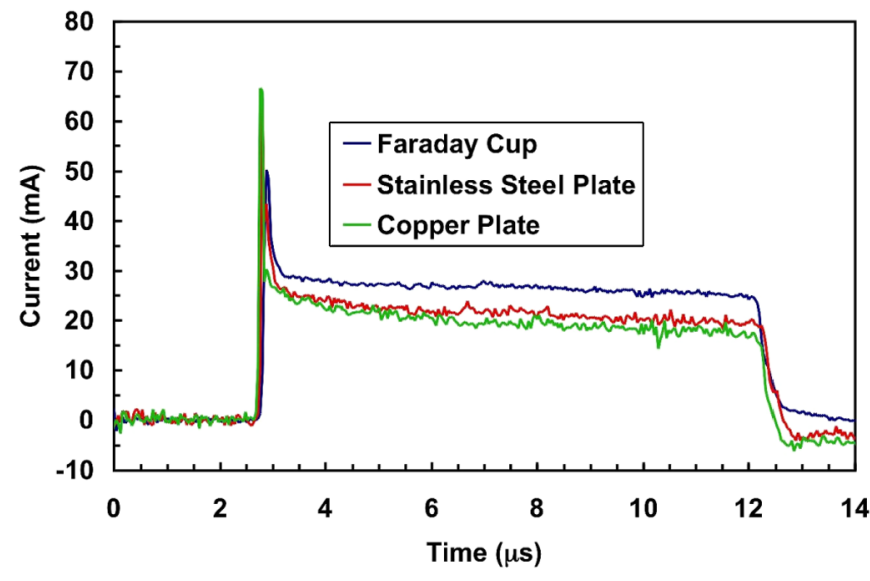

FIG. 16. (Color) Beam current signals collected by the Faraday cup (blue), stainless steel plate (red), and copper plate (green) with both parallel plates biased negatively.

gas expanding from the center of the target could escape. $\mathrm{H}_{2}$ gas was the likely candidate of gas to be desorbed from stainless steel at a rate of $\sim 3000 \mathrm{H}_{2}$ molecules $/ \mathrm{K}^{+}$ion based on measurements with a higher kinetic energy $\mathrm{K}^{+}$ ion beam [21]. It is assumed from these measurements and simulations that the subsequently ionized gas is a mixture of $\mathrm{H}_{2}^{+}$and $\mathrm{H}^{+}$.

The calculated time for a positive current to appear on the parallel plates due to ionized $\mathrm{H}_{2}$ was about $1 \mu \mathrm{s}$. On the STX there was a positive capacitive image current when the beam head passed through the diagnostic at $2.5 \mu \mathrm{s}$ followed by a rising positive current less than $1 \mu$ s later [Fig. 17(a)]. The gas initially desorbed and ionized $\left(\mathrm{I}_{H}\right)$ was measured immediately after the beam head at $3.2 \mu \mathrm{s}$. $\mathrm{I}_{H}$ measured with the stainless steel target was $20 \%$ of the $\mathrm{K}^{+}$ion current $\left(\mathrm{I}_{b}\right)$ with the plates biased to $-1 \mathrm{kV}$ and increased linearly to $>30 \%$ when the plates were biased to $-10 \mathrm{kV}$ [Fig. 17(b)]. These values were slightly higher for copper, $\mathrm{I}_{H} / \mathrm{I}_{b}=25 \%$ at $-1 \mathrm{kV}$ and increased linearly to $39 \%$ at $-10 \mathrm{kV}$. This bias dependence suggests a saturation of the measured gas initially desorbed and ionized may require a bias above $10 \mathrm{kV}$. Assuming a similar amount of gas was desorbed per $\mathrm{K}^{+}$ ion as in Ref. [21], then a very low fraction $\left(\sim 10^{-4}\right)$ of the gas molecules are ionized and collected on the parallel plates. This suggests the ionization cross section measured with a higher kinetic energy $\mathrm{K}^{+}$ion beam $\left(\sigma_{i z}=1.6 \times\right.$ $10^{-20} \mathrm{~m}^{2}$ ) [19] is slightly lower than what is actually the case for the beam in these experiments.

The initially steep slope of the ionized gas current at $3.2 \mu$ s decreased as a function of time [Fig. 17(a)]. This was most likely due to expansion of the gas transversely. The beam was only $1.5 \mathrm{~cm}$ wide, which is small compared to the distance between the plates $(7.5 \mathrm{~cm})$, so the gas did not continue to be ionized at the same rate as it was initially. Nonetheless there was still a positive slope and the total ion current (or charge) from the gas desorbed off 

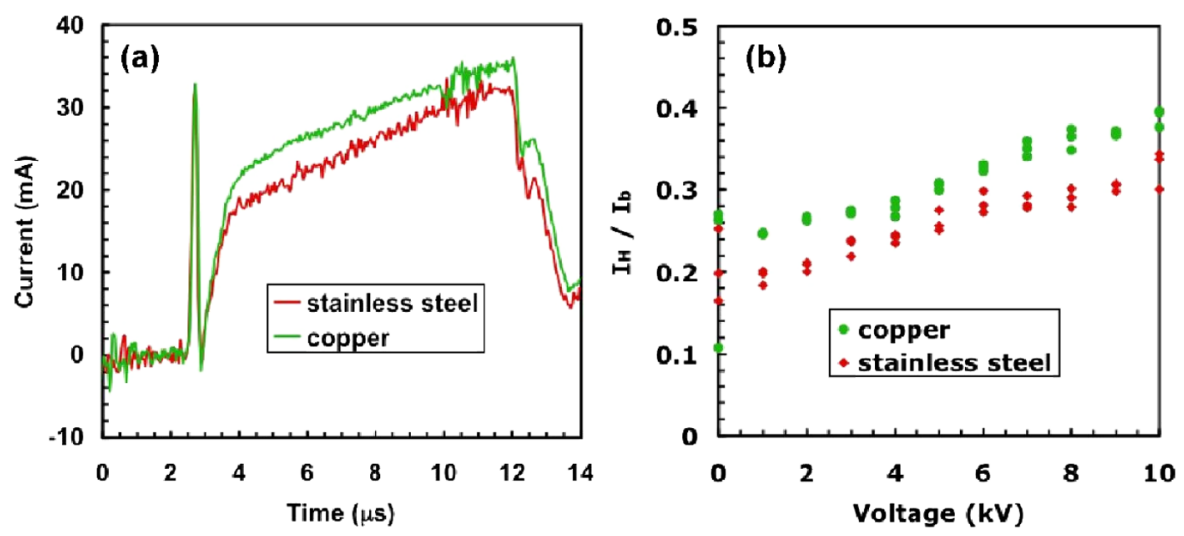

FIG. 17. (Color) (a) Ionized gas current collected on the parallel plates biased at $-10 \mathrm{kV}$ when intercepting the beam with a stainless steel plate (red) and a copper plate (green); (b) ratio of the ionized gas current $\left(\mathrm{I}_{H}\right.$ ) collected on the negatively biased parallel plates to the beam current $\left(\mathrm{I}_{b}\right)$ versus bias potential over a $200 \mathrm{~ns}$ gate at $3.2 \mu \mathrm{s}$.

of the stainless steel plate was $87 \%$ of the total $\mathrm{K}^{+}$ion current and for the copper plate it was almost equal to the total $\mathrm{K}^{+}$ion current.

The ionized gas current measured on the parallel plates was used to quantify the ionized gas line charge density $\left(\lambda_{H}=\mathrm{I}_{H} / \mathrm{v}_{H}\right)$ immediately after the beam head and at the end of the beam pulse. Assuming the gas ions are $\mathrm{H}^{+}$and they have purely kinetic energy $(10 \mathrm{keV})$ provided by the potential difference from the parallel plates to grounded intercepting electrode, then $\mathrm{H}^{+}$ions have $\mathrm{a}_{H}=1.39 \times$ $10^{6} \mathrm{~m} / \mathrm{s}$. Initially, this yields $\lambda_{H}=6 \mathrm{nC} / \mathrm{m}$ when intercepting the beam with the stainless steel plate and $7.2 \mathrm{nC} / \mathrm{m}$ when intercepting the beam with the copper plate (Table II). These measurements directly after the beam head have an uncertainty of $<5 \%$. Including the rest of the beam pulse, $\lambda_{H}$ increases to $16.2 \mathrm{nC} / \mathrm{m}$ for the stainless steel case and $18.3 \mathrm{nC} / \mathrm{m}$ for the copper case with an uncertainty of about $1 \%$. Immediately after the beam head and at the end of the beam pulse, there are about $15 \%$ more gas ions collected when intercepting the beam with copper versus stainless steel. This demonstrates a slight material dependence for two plates with identical surface preparation. Although, a more detailed study of different surface preparations may yield different results, the objective was to study different materials with our standard vacuum surface preparation.

The ionized gas density $\left(\mathrm{n}_{H}\right)$ is inferred using the beam line charge density $\left(\lambda_{b}=21 \mathrm{nC} / \mathrm{m}\right)$ and the values calcu-

TABLE II. Calculated ionized gas densities immediately after the beam head (3.2-3.4 $\mu \mathrm{s})$ and at the end of the beam pulse when intercepting the beam with stainless steel and copper plates.

\begin{tabular}{lcccc}
\hline \hline Time $(\mu \mathrm{s})$ & \multicolumn{2}{c}{$3.2-3.4$} & \multicolumn{2}{c}{$2.5-12.5$} \\
Material & $\mathrm{SS}$ & $\mathrm{Cu}$ & $\mathrm{SS}$ & $\mathrm{Cu}$ \\
\hline$\lambda_{H}(\mathrm{nC} / \mathrm{m})$ & 6.05 & 7.19 & 16.24 & 18.29 \\
$\mathrm{n}_{H}\left(\mathrm{~cm}^{-3}\right)$ & $2.14 \times 10^{8}$ & $2.54 \times 10^{8}$ & $5.75 \times 10^{8}$ & $6.47 \times 10^{8}$ \\
\hline \hline
\end{tabular}

lated above assuming $\mathrm{n}_{H} / \mathrm{n}_{b} \propto \lambda_{H} / \lambda_{b}$, where $\mathrm{n}_{b}(7.4 \times$ $10^{8} \mathrm{~cm}^{-3}$ ) is the beam density at the intercepting diagnostic. The resulting densities are shown in Table II. $\mathrm{n}_{H}$ early in the beam pulse is only about $30 \%$ of the beam density but increases to $77 \%$ of the beam density for the stainless steel case and $87 \%$ for the copper case. This time dependence is expected from the slope in Fig. 17(a) and the final densities are close to the beam density which is in good agreement with what is predicted for beam-induced gas desorption by particle in the cell simulations using the Warp code $[22,39]$.

\section{B. Electron emission measurements}

Biasing the parallel plates in a dipole configuration collected all of the secondary electrons due to beaminduced emission and ionization of desorbed gas on the positively biased plate and a fraction of the desorbed and further ionized hydrogen on the grounded plate. This experiment provided the number of electrons released per ion for normal incidence $\left(\gamma_{\mathrm{se}}\right)$. Assuming the cross sections for beam or gas ion recombination and second ionization are small, the accumulated electron current from 3.4-4 $\mu$ s had a slope in time that was proportional to the product of the desorbed gas density $\left(\mathrm{n}_{H}\right)$ and the ionization cross section $\left(\sigma_{i z}\right)$.

A positive capacitive image current appeared when the beam passed through the diagnostic at $2.5 \mu$ s followed by an almost instantaneous negative capacitive spike from secondary electrons released from the intercepting plate by the beam head [Fig. 18(a)]. Once the head of the beam had passed, the beam current and envelope stabilized providing a consistent determination of the number of secondary electrons. The secondary emission coefficient $\left(\gamma_{\mathrm{se}}\right)$, the ratio of the secondary electron current $\left(\mathrm{I}_{e}\right)$ collected on the positively biased parallel plate to the beam current $\left(\mathrm{I}_{b}\right)$, was measured immediately after the beam head at $3.2 \mu \mathrm{s}$ over a 200 ns gate [Fig. 18(b)]. The stainless steel target produced a $\gamma_{\mathrm{se}}=4.42 \pm 0.05$ with the parallel plate 

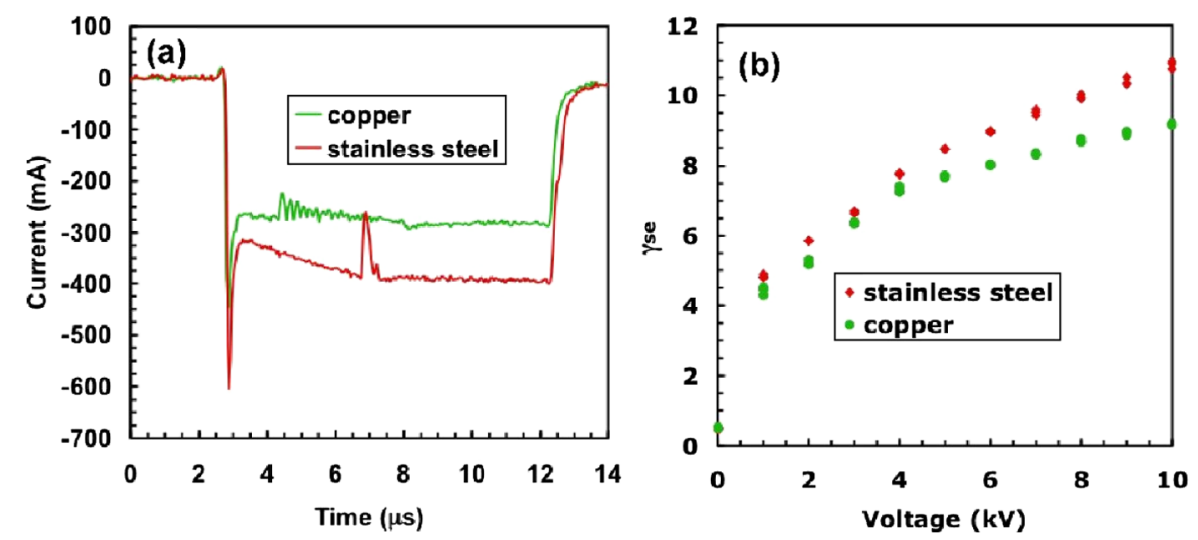

FIG. 18. (Color) (a) Secondary electron current collected on the parallel plate biased at $+10 \mathrm{kV}$ when the beam is intercepted with a stainless steel plate (red); and a copper plate (green). (b) Secondary emission coefficient versus bias potential over a 200 ns gate at $3.2 \mu \mathrm{s}$.

biased to $+1 \mathrm{kV}$ and increased to $10.87 \pm 0.11$ when the plate was biased to $+10 \mathrm{kV}$. The value was about the same for copper at $+1 \mathrm{kV}$, but increased at a slower rate to $9.18 \pm 0.02$ at $+10 \mathrm{kV}$. This bias dependence suggests a saturation of the measured secondary electron current may require a bias above $10 \mathrm{kV}$ as was seen with the ionized gas measurements [Fig. 17(b)].

A large difference in the dynamics of the electron emission was seen when intercepting the beam with stainless steel versus copper. When the stainless steel plate intercepted the beam, there was an initial negative slope in the electron current at $3.2 \mu \mathrm{s}$ that decreased (became less negative) as a function of time until $7 \mu$ s when a small positive spike was observed [Fig. 18(a)]. At about $7.5 \mu \mathrm{s}$, the electron current recovered and saturated at $\sim 390 \mathrm{~mA}$. Intercepting the beam with the copper plate displayed a different phenomena; a flat electron current was observed at $3.2 \mu \mathrm{s}$ followed by a high frequency oscillation at $4.5 \mu \mathrm{s}$. These characteristics were also seen at lower bias voltages for both materials; a detailed description of the physics of these phenomena is beyond the scope of this paper and will be published later.

The secondary electron current measured on the positive parallel plate was used to quantify the electron line charge density $\left(\lambda_{e}=\mathrm{I}_{e} / \mathrm{v}_{e}\right)$ immediately after the beam head and at the end of the beam pulse. Assuming the electrons have purely kinetic energy $(10 \mathrm{keV})$ provided by the potential difference from the positively biased parallel plate to grounded intercepting electrode, then they have a $\mathrm{v}_{e}=$ $5.94 \times 10^{7} \mathrm{~m} / \mathrm{s}$. Initially, this yields $\lambda_{e}=4.69 \mathrm{nC} / \mathrm{m}$ when intercepting the beam with the stainless steel plate and $3.96 \mathrm{nC} / \mathrm{m}$ when intercepting the beam with the copper plate (Table III). These measurements directly after the beam head have an uncertainty of about $1 \%$. Including the rest of the beam pulse $\lambda_{e}$ increases to $5.83 \mathrm{nC} / \mathrm{m}$ for the stainless steel case and $4.29 \mathrm{nC} / \mathrm{m}$ for the copper case with an uncertainty of $<1 \%$. Immediately after the beam head and at the end of the beam pulse, there are $\geq 15 \%$ electrons collected when intercepting the beam with stainless steel versus copper, again showing a slight material dependence.

Similar to $\mathrm{n}_{H}$, the electron density $\left(\mathrm{n}_{e}\right)$ is inferred using $\lambda_{b}$ and the values calculated above assuming $\mathrm{n}_{e} / \mathrm{n}_{b} \propto$ $\lambda_{e} / \lambda_{b}$ (Table III). Early in the beam pulse $\mathrm{n}_{e}$ is only about $22 \%$ of the beam density but increases to $28 \%$ of the beam density for the stainless steel target. Intercepting the beam with the copper plate $\mathrm{n}_{e}$ is only about $20 \%$ of the beam density throughout the whole beam pulse. Unlike the measured ionized hydrogen gas, there is not much time dependence in the measured electron densities. However, they are on the same order of magnitude as the beam density and that is in good agreement with what is predicted by Warp simulations of beam-induced gas desorption $[22,39]$.

These measurements demonstrate a difference in the dynamics of the ionized gas and electron currents measured and a slight material dependence. Measurements from a residual gas analyzer with a higher kinetic energy $\mathrm{K}^{+}$ion beam normally incident upon stainless steel indicate that the dominant gas species desorbed is hydrogen [21]. The next closest amount, which is nearly an order of magnitude less, had an atomic count of 28 which could be $\mathrm{N}_{2}$ or CO gas. Assuming hydrogen gas is the dominant species desorbed from the copper target, it appears from the ionized gas measurements that $15 \%$ more hydrogen is desorbed from the copper target and then ionized by the beam. However, the number of electrons emitted is $\geq 15 \%$

TABLE III. Calculated secondary emission coefficient and electron densities immediately after the beam head (3.2-3.4 $\mu \mathrm{s}$ ) and at the end of the beam pulse when intercepting the beam with stainless steel and copper plates.

\begin{tabular}{lcccc}
\hline \hline Time $(\mu \mathrm{s})$ & \multicolumn{2}{c}{$3.2-3.4$} & \multicolumn{2}{c}{$2.5-12.5$} \\
Material & $\mathrm{SS}$ & $\mathrm{Cu}$ & $\mathrm{SS}$ & $\mathrm{Cu}$ \\
\hline$\gamma_{\mathrm{se}}$ & 10.87 & 9.18 & $\ldots$ & $\ldots$ \\
$\lambda_{e}(\mathrm{nC} / \mathrm{m})$ & 4.69 & 3.96 & 5.83 & 4.29 \\
$\mathrm{n}_{e}\left(\mathrm{~cm}^{-3}\right)$ & $1.66 \times 10^{8}$ & $1.40 \times 10^{8}$ & $2.06 \times 10^{8}$ & $1.52 \times 10^{8}$ \\
\hline \hline
\end{tabular}


higher when intercepting the beam with stainless steel versus copper. These results make it difficult to conclude whether one material is more suitable than the other and further investigation may be necessary.

\section{CONCLUSIONS}

Electron cloud studies were successfully conducted in a solenoid lattice using cylindrical electrodes that intercepted the expanding magnetic flux from the solenoids. Beam dynamics measurements and measurements from the electrodes confirmed that the current-reducing aperture used in the experiments provided an $\mathrm{n}_{e} \sim 0.01 \mathrm{n}_{b}$ enough to partially neutralize the beam and cause the emittance to grow $\geq 40 \%$. Beam dynamics measurements proved that using the electrodes to clear these electrons was effective, prevented partial neutralization, and reduced the measured emittance so that it was conserved throughout the lattice.

The dynamics of beam-induced gas desorption, ionization, and electron emission for normal incidence was characterized for a $10 \mu \mathrm{s}$, singly charged $\mathrm{K}^{+}$ion bunch at an ion energy of $0.3 \mathrm{MeV}$ and current of $26 \mathrm{~mA}$. This beam provided $1.6 \times 10^{12}$ ions/pulse at a repetition rate of $0.05 \mathrm{~Hz}$. These measurements showed the gas cloud continues to expand as a function of time and the dynamics are dependent upon the incident material and the bias voltage. For a single pulse the gas desorbed and ionized reached $87 \%$ of the total $\mathrm{K}^{+}$ion current for the stainless steel target by the end of the pulse and $98 \%$ for the copper target. The measured secondary emission coefficient for the stainless steel target was 10.87 and for copper was 9.18. For each of the targets the total ionized gas and electron densities approached the beam density.

\section{ACKNOWLEDGMENTS}

This work was supported by the Director, Office of Science, Office of Fusion Energy Sciences, of the U.S. Department of Energy under Contract No. DE-AC0205H11231. We wish to thank Tak Katayanagi, Eugene Flor, Michael Dickinson, Cory Lee, Wayne Greenway, Matthaeus Leitner, Will Waldron, David Baca, Craig Rogers, Ed Romero, and Andy Faltens for their continued technical support.

[1] G. Budker, G. Dimov, and V. Dudnikov, Sov. At. Energy 22, 5 (1967).

[2] O. Gröbner, in Proceedings of the 10th International Conference on High-Energy Accelerators, Protvino, Russia (Institute of High Energy Physics, Protvino, 1977), p. 277.

[3] M. Izawa, Y. Sato, and T. Toyomasu, Phys. Rev. Lett. 74, 5044 (1995).

[4] K. Ohmi, Phys. Rev. Lett. 75, 1526 (1995).
[5] W. T. Weng et al., in Proceedings of the Particle Accelerator Conference, Vancouver, Canada, 1997, p. 970, http://www.JACoW.org/.

[6] R.J. Macek et al., in Proceedings of the Particle Accelerator Conference, Chicago, IL, 2001, p. 688, http://www.JACoW.org/.

[7] M. A. Furman, LBNL Report No. 50765, 2002.

[8] S. Y. Zhang et al., in Proceedings of the European Particle Accelerator Conference, Lucerne, Switzerland, 2004, p. 947, http://www.JACoW.org/.

[9] J. W. Flanagan et al., Phys. Rev. Lett. 94, 054801 (2005).

[10] R. J. Macek and A. A. Browman, in Proceedings of the Particle Accelerator Conference, Knoxville, TN, 2005, p. 2547, http://www.JACoW.org/.

[11] D. Edwards, in Proceedings of the Particle Accelerator Conference, San Francisco, CA, 1979, p. 4089, http:// www.JACoW.org/.

[12] P. Thieberger et al., Phys. Rev. ST Accel. Beams 7, 093201 (2004).

[13] A.W. Molvik et al., Phys. Rev. ST Accel. Beams 7, 093202 (2004).

[14] E. Mahner et al., Phys. Rev. ST Accel. Beams 7, 103202 (2004).

[15] E. Mahner et al., Phys. Rev. ST Accel. Beams 8, 053201 (2005).

[16] H. Huang et al., in Proceedings of the European Particle Accelerator Conference, Edinburgh, Scotland, 2006, p. 583, http://www.JACoW.org/.

[17] M. Bender et al., in Proceedings of the European Particle Accelerator Conference, Edinburgh, Scotland, 2006, p. 1423, http://www.JACoW.org/.

[18] M. Kireeff Covo et al., Phys. Rev. ST Accel. Beams 9, 063201 (2006).

[19] M. Kireeff Covo et al., Phys. Rev. Lett. 97, 054801 (2006).

[20] A. W. Molvik et al., Phys. Rev. Lett. 98, 064801 (2007).

[21] F. M. Bieniosek et al., Phys. Rev. ST Accel. Beams 10, 093201 (2007).

[22] W. M. Sharp et al., Nucl. Instrum. Methods Phys. Res., Sect. A 577, 146 (2007).

[23] J.E. Coleman et al., "Matching and transporting an intense ion beam through a solenoid focusing channel," Phys. Rev. ST Accel. Beams (to be published).

[24] R. I. Ewing, Phys. Rev. 166, 324 (1968).

[25] A. L. Hanson et al., J. Vac. Sci. Technol. A 19, 2116 (2001).

[26] E. Mahner et al., in Proceedings of the European Particle Accelerator Conference, Paris, France, 2002, p. 2568, http://www.JACoW.org/.

[27] E. Mahner et al., Phys. Rev. ST Accel. Beams 6, 013201 (2003).

[28] H. Kollmus et al., GSI Scientific Report 2004 ACCSOPD-09, available at http://www.gsi.de/informationen/ wti/library/scientificreport2004/PAPERS/ACCS-OPD09.pdf.

[29] H. Kollmus et al., in Proceedings of the European Particle Accelerator Conference, Edinburgh, Scotland, 2006, p. 1426, http://www.JACoW.org/.

[30] P. K. Roy et al., Phys. Rev. Lett. 95, 234801 (2005).

[31] P. A. Seidl et al., Nucl. Instrum. Methods Phys. Res., Sect. A 577, 215 (2007). 
[32] J.E. Coleman et al., in Proceedings of the Particle Accelerator Conference, Albuquerque, NM, 2007, p. 3516, http://www.JACoW.org/.

[33] D. Shuman et al., in Proceedings of the Particle Accelerator Conference, Knoxville, TN, 2005, p. 3798, http://www.JACoW.org/.

[34] F. M. Bieniosek et al., Nucl. Instrum. Methods Phys. Res., Sect. A 544, 268 (2005).

[35] S. Eylon et al., in Proceedings of the Particle Accelerator
Conference, Portland, OR, 2003, p. 2616, http:// www.JACoW.org/.

[36] Y.-J. Chen et al., Nucl. Instrum. Methods Phys. Res., Sect. A 292, 455 (1990).

[37] Y.-J. Chen et al., in Proceedings of the Particle Accelerator Conference, San Francisco, CA, 1991, p. 3100.

[38] Y.-J. Chen, Nucl. Instrum. Methods Phys. Res., Sect. A 398, 139 (1997).

[39] D. P. Grote et al., AIP Conf. Proc. 749, 55 (2005). 